\title{
Pharmacological inhibition of the ideal apical sodium-dependent bile acid transporter ASBT ameliorates cholestatic liver disease in mice
}

\author{
Ahmed Ghallab ${ }^{1}[$ \\ Received: 17 September 2019 / Accepted: 18 September 2019 / Published online: 21 September 2019 \\ (c) Springer-Verlag GmbH Germany, part of Springer Nature 2019
}

Cholestatic liver disease and cholestasis induced by chemicals represent a major research field in toxicology (Rodrigues et al. 2018; Reif et al. 2015; Leist et al. 2017; Godoy et al. 2013) and much effort has been invested to identify possible therapies (Jahn et al. 2018; Cariello et al. 2017; Marzioni et al. 2009; Zhou et al. 2016; Svinka et al. 2017). One strategy is to reduce the concentration of circulating bile acids (Jansen et al. 2017; Godoy et al. 2013). This can be achieved by reducing biosynthesis of bile acids, e.g. by FXR agonists. Further strategies are to decrease the intestinal re-uptake of bile acids by sequestrants, resins that bind bile acids in the intestinal lumen or by inhibiting ileal transporters that reabsorb bile acids (Jahn et al. 2018). The latter has been demonstrated as an efficient strategy in a landmark paper published already in 2006 (Baghdasaryan et al. 2016). The authors used Mdr2 ${ }^{-/-}$mice, a model of cholestatic liver injury and sclerosing cholangitis, to test an inhibitor (A4250) of the sodium-dependent carrier ASBT that transports bile acids from the intestinal lumen into intestinal epithelial cells from where they reach the intestinal capillaries. Interestingly, A4250 increased fecal bile acid excretion without causing diarrhea (Baghdasaryan et al. 2016). Concentrations of bile acids (TCA, T $\beta$ MCA) were clearly reduced in the bile. Liver damage as evidenced by liver enzymes and histological changes as well as bile duct proliferation were strongly reduced (Baghdasaryan et al. 2016). The results of Baghdasaryan and colleagues represent a positive surprise, since one may expect that the desired consequences of increased intestinal bile acid excretion may have been compensated via increased bile acid synthesis of the liver; however, this did not seem to be the case. Nevertheless, the combination of ASBT inhibitors and FXR agonists (to

Ahmed Ghallab

ghallab@vet.svu.edu.eg

1 Forensic Medicine and Toxicology Department, Faculty of Veterinary Medicine, South Valley University, Qena, Egypt block bile acid synthesis in hepatocyte) will be an interesting future perspective.

Increased bile acid concentrations in the biliary tract have been shown to lead to ruptures of the apical hepatocyte membrane and to bile infarcts as early key events (Ghallab et al. 2019), while long-term obstruction causes adaptive remodeling of interlobular bile ducts, also named ductular response and to periportal liver fibrosis (Vartak et al. 2016). In future, it will be interesting to learn, by which degree the adverse consequences of cholestasis can be reduced, when the circulating bile acid pool will be reduced to almost normal levels by ASBT inhibitors and FXR agonists.

\section{Compliance with ethical standards}

Conflict of interest The author declares that he has no conflict of interest.

\section{References}

Baghdasaryan A, Fuchs CD, Österreicher CH et al (2016) Inhibition of intestinal bile acid absorption improves cholestatic liver and bile duct injury in a mouse model of sclerosing cholangitis. J Hepatol 64(3):674-681. https://doi.org/10.1016/j.jhep.2015.10.024

Cariello M, Peres C, Zerlotin R, Porru E, Sabbà C, Roda A, Moschetta A (2017) Long-term administration of nuclear bile acid receptor FXR agonist prevents spontaneous hepatocarcinogenesis in Abcb4(-/-) mice. Sci Rep 7:11203

Ghallab A, Hofmann U, Sezgin S et al (2019) Bile microinfarcts in cholestasis are initiated by rupture of the apical hepatocyte membrane and cause shunting of bile to sinusoidal blood. Hepatology 69(2):666-683. https://doi.org/10.1002/hep.30213

Godoy P, Hewitt NJ, Albrecht U et al (2013) Recent advances in 2D and $3 \mathrm{D}$ in vitro systems using primary hepatocytes, alternative hepatocyte sources and non-parenchymal liver cells and their use in investigating mechanisms of hepatotoxicity, cell signaling and ADME. Arch Toxicol 87(8):1315-1530. https://doi.org/10.1007/ s00204-013-1078-5 (review)

Jahn D, Marzioni M, Geier A (2018) Manipulation of the gut-liver axis by interruption of bile acid recirculation: an option for the 
treatment of sclerosing cholangitis? Gut 67(9):1565-1567. https ://doi.org/10.1136/gutjnl-2018-316375

Jansen PL, Ghallab A, Vartak N, Reif R, Schaap FG, Hampe J, Hengstler JG (2017) The ascending pathophysiology of cholestatic liver disease. Hepatology 65(2):722-738. https://doi.org/10.1002/ hep. 28965

Leist M, Ghallab A, Graepel R et al (2017) Adverse outcome pathways: opportunities, limitations and open questions. Arch Toxicol 91(11):3477-3505. https://doi.org/10.1007/s00204-017-2045-3

Marzioni M, Alpini G, Saccomanno S et al (2009) Exendin-4, a glucagon-like peptide 1 receptor agonist, protects cholangiocytes from apoptosis. Gut 58(7):990-997

Reif R, Karlsson J, Günther G, Beattie L et al (2015) Bile canalicular dynamics in hepatocyte sandwich cultures. Arch Toxicol 89(10):1861-1870. https://doi.org/10.1007/s00204-015-1575-9

Rodrigues RM, Kollipara L, Chaudhari U et al (2018) Omics-based responses induced by bosentan in human hepatoma HepaRG cell cultures. Arch Toxicol 92(6):1939-1952. https://doi.org/10.1007/ s00204-018-2214-z
Svinka J, Pflügler S, Mair M et al (2017) Epidermal growth factor signaling protects from cholestatic liver injury and fibrosis. J Mol Med (Berl) 95(1):109-117. https://doi.org/10.1007/s00109-016-1462-8

Vartak N, Damle-Vartak A, Richter B, Dirsch O, Dahmen U, Hammad S, Hengstler JG (2016) Cholestasis-induced adaptive remodeling of interlobular bile ducts. Hepatology 63(3):951-964. https://doi. org/10.1002/hep.28373

Zhou M, Learned RM, Rossi SJ, DePaoli AM, Tian H, Ling L (2016) Engineered fibroblast growth factor 19 reduces liver injury and resolves sclerosing cholangitis in Mdr2-deficient mice. Hepatology 63(3):914-929. https://doi.org/10.1002/hep.28257

Publisher's Note Springer Nature remains neutral with regard to jurisdictional claims in published maps and institutional affiliations. 